\title{
The Prevalence and risk factors of osteoporosis among the elderly in Hamadan province: A cross sectional study
}

\author{
Parvin Cheraghi ${ }^{1}$, Zahra Cheraghi*2, Shiva Bozorgmehr ${ }^{3}$
}

Received: 28 May 2017

Published: 11 Nov 2018

\begin{abstract}
Background: Osteoporosis is the most common metabolic bone disease and is a public health issue, particularly among the elderly, across the world. Given the significance of the disease in causing disability and, in particular, its dangers in old age, we aimed to examine osteoporosis and its determinant factors among the elderly.

Methods: We conducted a cross sectional study in the province of Hamadan from September 2015 to March 2016 on all the elderly men and women covered by 'Integrated and Comprehensive Elderly Care Program'. The data required for this study was collected through an aging health care checklist. To estimate the adjusted association of potential risk factors and other confounding variables of osteoporosis, multiple logistic regression was used at a significance level of 5\%.

Results: In this cross sectional study, 1779 elderly men and women aged 60 years and over were studied. The prevalence of osteoporosis was $7.99 \%$ (95\%CI:7.79-8.18), which was higher among women than in men $(8.08 \% \mathrm{vs.} 7.83 \%)$. The factors that raised the probability of osteoporosis were as follow: aging (OR=1.05, 95\% CI: 1.02-1.07, $\mathrm{p}<0.001)$, low education (OR=1.96, 95\% CI:1.02-3.84, $\mathrm{p}=0.04)$, living in urban areas $(\mathrm{OR}=2.82,95 \% \mathrm{CI}: 1.93-4.11, \mathrm{p}<0.001)$, smoking $(\mathrm{OR}=2.39,95 \% \mathrm{CI}: 1.42-4.04$, $\mathrm{p}<0.001)$, and family history of osteoporosis $(\mathrm{OR}=1.95,95 \% \mathrm{CI}: 1.07-3.54, \mathrm{p}=0.03)$.

Conclusion: Based on our results, aging, low education level, living in urban areas, being a cigarette smoker, and having a family history of osteoporosis were all predicting factors for osteoporosis among the elderly.
\end{abstract}

Keywords: Osteoporosis, Elderly, Prevalence, Iran, Hamadan

Conflicts of Interest: None declared

Funding: Hamadan University of Medical Sciences, Hamadan, Iran

\section{*This work has been published under CC BY-NC-SA 1.0 license.}

Copyright $\odot$ Iran University of Medical Sciences

Cite this article as: Cheraghi P, Cheraghi Z, Bozorgmehr Sh. The Prevalence and risk factors of osteoporosis among the elderly in Hamadan province: A cross sectional study. Med J Islam Repub Iran. 2018 (11 Nov);32:111. https://doi.org/10.14196/mjiri.32.111

\section{Introduction}

Osteoporosis is the most common metabolic bone disease and is considered a public health issue throughout the world; its most outstanding characteristic is reduced bone density, which makes the individual prone to fractures (1).

There are different methods of evaluating bone density; however, the current method is the non-invasive, simple, and harmless method of dual-energy X-ray absorptiometry

Corresponding author: Dr Zahra Cheraghi, z.cheraghi@umsha.ac.ir

1. Department of Genterology, University of Social Welfare and Rehabilitation Sciences, Tehran, Iran, \& Department of Health Education and Promotion, School of Public Health, Hamadan University of Medical Sciences, Hamadan, Iran

2. Department of Epidemiology, Non-communicable Disease Center, School of Public Health, Hamadan University of Medical Sciences, Hamadan, Iran

3. Health Vice-Chancellors, Hamadan University of Medical Sciences, Hamadan, Iran
(DEXA). According to the World Health Organization's criteria, it is normal when the T criterion is greater than -1 ; however, osteopenia occurs when it is between -1 and -2.5 , and osteoporosis occurs when $\mathrm{T}$ is lower than -2.5 (In this state, bone density is $2.5 \mathrm{SD}<$ mean for a 30 -year-old male or female) (2).

Osteoporosis is known as a multifactorial disease, such

$\uparrow$ What is "already known” in this topic:

Osteoporosis is the most common metabolic bone disease and is a public health issue, particularly among the elderly, across the world. Given the significance of osteoporosis in creating disability, particularly the associated risks of the disease in old age, we aimed to investigate the prevalence and determinant factors of osteoporosis among the elderly.

$\rightarrow$ What this article adds:

The prevalence of osteoporosis was $7.99 \%$, which was higher among women than in men. Based on our findings, aging, low education level, living in urban areas, cigarette smoking, and having a family history of osteoporosis were predictive factors for osteoporosis among the elderly. 
that certain diseases, such as hyperthyroidism, gonadal dysfunction, rheumatoid arthritis, Cushing's syndrome, and the long-term use of certain drugs, such as cortisone, can cause it. Other factors also contribute to the development of osteoporosis, such as physical inactivity or being underweight more than $10 \%$ compared to the weight in youths or a BMI lower than 19, hereditary factors, and alcohol addiction (3-5).

This silent disease has affected 200 million people around the world, such that in the US alone $5 \%$ of the population aged above 50 years have osteoporosis, and 1.5 million cases of osteoporotic fractures occur annually (6). In Iran, in 2001, approximately $15 \%$ of the population had osteoporosis, which increased to $34 \%$ in 2011 . Based on systematic review studies in Iran, the overall prevalence of osteoporosis is $17 \%$. Moreover, according to studies conducted on the Iranian population, there is considerable prevalence of osteoporosis among men and women aged less than 50 years, which perhaps raises the probability of osteoporotic fractures $(7,8)$. In Iran, approximately $50 \%$ of men and $60 \%$ of women have varying degrees of mild osteoporosis. Recent findings have shown that the prevalence of osteoporosis is rising more steeply among Iranian men, and since morbidity and mortality associated with fractures are more common among men than in women, the significance of the issue becomes greater (9).

Osteoporosis is an important cause of disease and disability in the elderly and occurs in approximately 55\% of women aged over 50 years, and the treatment costs imposed as a result of bone fractures are very high. After the age of 50 , the risk of hip and vertebral fractures is thrice as much, and the risk of wrist fracture is 6 times as much in women than in men. Considering the novel knowledge and findings on this disease, it is potentially preventable and can be detected and cured before a fracture occurs. Thus, its timely diagnosis and prevention of progress is the main goal of geriatric medicine (10-12).

Given the significance of the aforementioned disease in creating disability, particularly the associated risks of the disease in old age, we aimed to investigate the prevalence and determinant factors of osteoporosis among the elderly. Also, this study was conducted for the first time in Hamadan province.

\section{Methods \\ Data}

A cross sectional study was conducted from September 2015 to March 2016 in Hamadan province on the entire elderly population covered by the Integrated and Comprehensive Elderly Care Program (ICECP). The elderly's data were collected starting from the beginning of this program. The Comprehensive Elderly Care Program has been designed under the title 'Integrated and Comprehensive Elderly Care Program' for physicians and non-physicians. When an elderly visits a doctor to receive care, the ICECP guideline for non-physicians is used to care for him/her, and cases of referral are referred according to the educational guide.

Then, if the elderly is recognized to have one or more diseases that require specialized services, based on the educational guide, s/he will receive higher level care and will be included in the referral cycle. If the elderly has a disease that requires health services, s/he will be included in the cycle of follow-ups.

\section{Inclusion criteria}

Hamadan residents aged 60 and over, who are covered by the ICECP.

\section{Measurement of outcome}

Here, a T-score lower than -2.5 and in the absence of one of the following was considered as a definite diagnosis of osteoporosis: "history of fracture after 40 years following small or average injuries" or "history of documented osteoporosis or use of cortisone drugs for a minimum of 3 months".

\section{Measurement of other variables}

Age, gender, education (literate, illiterate), living status (with family, alone), habitat (urban vs rural), BMI (underweight, normal, overweight, obese), smoking status, and family history of osteoporosis were also measured.

\section{Instrument}

The data required for this study were collected using the Periodic Elderly Care checklist prepared by Deputy of Health at Hamadan University of Medical Sciences who executes the ICECP in this province. Overall, the data used from the integrated program were as follow: cardiovascular diseases; hypertensive disorders; diabetes; psychological disorders, including depression, sleep disorders, osteoporosis; and urinary incontinence.

\section{Statistical analysis}

To estimate the associations of the variables in the model and to achieve the best fitness, we entered the quantitative variables as categorical, and again as continuous quantitative variables by considering other variables in the model. Next, we tested them with the LR-test (Chi-square, $\mathrm{df}=1$ ). If the test result was significant, then the variable in mind would have been entered as a categorical one in the model.

Data were analyzed using STATA 13 software at 95\% confidence interval. The crude odds ratios were extracted from the logistic regression model. The adjusted associations of the potential risk factors and other confounding variables in the occurrence of osteoporosis were extracted from multiple logistic regression model, and maximum likelihood estimator were applied at 5\% significance level.

\section{Results}

In this cross sectional study, 1779 elderly men and women aged over 60 years, with the mean age of $74.95 \pm 18.8$, were studied.

The majority of the participants were male $(60.5 \%)$, most of them $(85.2 \%)$ were illiterate, most $(90 \%)$ lived with their families, and the majority (81\%) lived in rural areas (Table $1)$.

Regarding BMI, almost half of the participants were in 


\begin{tabular}{|c|c|c|c|}
\hline Variables & $\begin{array}{c}\text { Controls } \\
\mathrm{N}(\%) \\
1637(92.01)\end{array}$ & $\begin{array}{c}\text { Cases } \\
\mathrm{N}(\%) \\
142(7.99)\end{array}$ & $\begin{array}{c}\text { Total } \\
\mathrm{N}=1779\end{array}$ \\
\hline \multicolumn{4}{|l|}{ Gender } \\
\hline Male & $674(39.5)$ & $55(38.7)$ & 702 \\
\hline Female & $990(60.5)$ & $87(61.3)$ & 1077 \\
\hline \multicolumn{4}{|l|}{ Education } \\
\hline literate & $242(14.8)$ & $11(7.8)$ & 253 \\
\hline Illiterate & $1395(85.2)$ & $131(92.2)$ & 1526 \\
\hline \multicolumn{4}{|l|}{ Living } \\
\hline With Family & 1438 (89.9) & $116(82.9)$ & 1554 \\
\hline Alone & $160(10.1)$ & $24(17.1)$ & 184 \\
\hline \multicolumn{4}{|l|}{ Habitat } \\
\hline Rural & $1323(80.8)$ & $86(60.6)$ & 1409 \\
\hline Urban & $314(19.2)$ & $56(39.4)$ & 370 \\
\hline \multicolumn{4}{|l|}{ BMI } \\
\hline Normal & $868(54.6)$ & $82(58.2)$ & 950 \\
\hline Overweight & $492(31.0)$ & $37(26.2)$ & 531 \\
\hline Obese & $230(14.4))$ & $22(15.6)$ & 252 \\
\hline \multicolumn{4}{|l|}{ Smoking status } \\
\hline No & $1494(91.2)$ & $119(83.8)$ & 1613 \\
\hline Yes & $143(8.8)$ & $23(16.2)$ & 166 \\
\hline \multicolumn{4}{|c|}{ Family history of osteoporosis } \\
\hline No & $1553(94.9)$ & $126(88.7)$ & 1679 \\
\hline Yes & $84(5.1)$ & $16(11.3)$ & 100 \\
\hline
\end{tabular}

Table 2. Risk factors of osteoporosis among elderly people in Hamadan

\begin{tabular}{lcccccc}
\hline \multirow{2}{*}{ Variables } & \multicolumn{3}{c}{ Univariate Model } & \multicolumn{3}{c}{ Multiple Model } \\
\cline { 2 - 7 } & $\mathrm{OR}_{\mathrm{C}}$ & $\mathrm{p}$ & $95 \% \mathrm{CI}$ & $\mathrm{OR}_{\mathrm{a}}$ & $\mathrm{p}$ & $95 \% \mathrm{CI}$ \\
\hline Age (year) & 1.05 & $<0.001$ & {$[1.03,1.07]$} & 1.05 & $<0.001$ & {$[1.02,1.07]$} \\
Gender (Female vs. Males) & 1.03 & 0.850 & {$[0.73,1.47]$} & 1.08 & 0.720 & {$[0.71,1.65]$} \\
Education (Literate vs Illiterate) & 0.48 & 0.020 & {$[0.26,0.91]$} & 0.51 & 0.040 & {$[0.26,0.98]$} \\
Living (With Family vs. Alone) & 0.54 & 0.010 & {$[0.34,0.36]$} & 0.69 & 0.160 & {$[0.41,1.16]$} \\
Habitat (Urban vs. Rural) & 2.74 & $<0.001$ & {$[1.92,3.92]$} & 2.82 & $<0.001$ & {$[1.93,4.11]$} \\
BMI & & & & & & \\
Overweight vs. normal & 0.79 & 0.260 & {$[0.23,1.90]$} & 0.84 & 0.410 & {$[0.54,1.28]$} \\
Obese vs. normal & 1.01 & 0.050 & {$[0.62,1.65]$} & 1.03 & 0.930 & {$[0.60,1.74]$} \\
Smoking (Yes vs. No) & 2.02 & 0.004 & {$[1.25,3.03]$} & 2.39 & $<0.001$ & {$[1.42,4.04]$} \\
Family history of osteoporosis (Yes vs. No) & 2.34 & 0.0032 & {$[1.33,4,11]$} & 1.95 & 0.030 & {$[1.07,3.54]$} \\
\hline OR: Crinyyyyyyyyyyy
\end{tabular}

OR: Crude odds ratio

$\mathrm{OR}_{\mathrm{a}}=$ Adjusted odds ratio

$\mathrm{OR}=1.95,95 \%$ CI: $1.07-3.54, \mathrm{p}=0.03$

the normal range; $31 \%$ were overweight, and only $14.4 \%$ were obese. The prevalence of cigarette smoking and family history of osteoporosis was $8.8 \%$ and $5.1 \%$, respectively.

The prevalence of osteoporosis was $7.99 \%$ (95\% CI: 7.79- 8.18). Overall, among the 1779 elderly male and female participants, osteoporosis was reported in 142 (7.99\%). The prevalence was greater among females than in males $(8.08 \%$ vs $7.83 \%)$.

We also studied the associations of some variables that potentially affect osteoporosis. Based on the univariate logistic regression results, the association of aging, low education level, high BMI, cigarette smoking, and a positive family history of osteoporosis were directly related to the occurrence of osteoporosis. Moreover, based on the multiple logistic regression result, the adjusted associations of some of the potential risk factors were as follow:

There was a significant direct association between the risk of osteoporosis and aging $(\mathrm{OR}=1.05,95 \% \mathrm{CI}: 1.02-$ $1.07, \mathrm{p}<0.001)$. The risk of osteoporosis was greater among women; however, it was not statistically significant. The risk was $49 \%$ lower among literate men and women compared to illiterate ones and was statistically significant
$(\mathrm{OR}=0.51,95 \% \mathrm{CI}: 0.26-0.98, \mathrm{p}=0.04)$. The risk of osteoporosis was 2.82 times greater among urban residents, compared to rural residents and was statistically significant $(\mathrm{OR}=2.82,95 \% \mathrm{CI}: 1.93-4.11, \mathrm{p}<0.001)$ (Table 2).

Moreover, those who smoked were 2.39 times more likely to have osteoporosis than those who did not; this association was statistically significant $(\mathrm{OR}=2.02,95 \%$ CI:1.25-3.03 p <0.001).

Those elderly individuals who had a family history of osteoporosis were * 1.95 times more likely to have osteoporosis than those who did not, the association was also statistically significant $\quad(* \mathrm{OR}=1.95, \quad 95 \% \quad \mathrm{CI}: 1.07-3.54$, $\mathrm{p}=0.03)$.

\section{Discussion}

In this cross sectional study, the overall prevalence of osteoporosis among the elderlies of Hamadan province was 7.99\% (95\% CI:7.79- 8.18), which was higher among women than in men $(8.08 \%$ vs $7.83 \%)$. Furthermore, we showed the adjusted associations of the potential risk factors affecting the occurrence of osteoporosis. Aging, low education level, living in urban areas, smoking, and a his- 
tory of osteoporosis were directly associated with the prevalence of osteoporosis. All these associations were statistically significant.

Although the higher prevalence of osteoporosis among women in our study was consistent with the findings of other studies $(13,14)$, it was lower than the expected value. Based on the results of a meta-analysis on the prevalence of osteoporosis in Iran, this figure was reported at 17\% (8). The considerably low figure observed in this study can be attributed to underreporting and/or inadequate monitoring of the elderly covered by the Elderly Care Program.

Based on the literature, aging increases the possibility of osteoporosis. With aging, bone density gradually decreases, such that after the age of 40 it falls by $0.5-1 \%$ annually. Our results are consistent with this finding $(15,16)$. However, in women, this increase in prevalence is strongly associated with the onset of menopause and drop in sex hormone levels. Thus, one would expect the prevalence to be higher among women than in men. In spite of being higher, this prevalence was not significant, which may be attributed to the inadequate power of our study.

We observed a significant statistical association between cigarette smoking and the risk of osteoporosis; smokers were 2.39 times more likely to have osteoporosis than nonsmokers. According to the literature, elderly persons who smoke were $30 \%-40 \%$ more likely to experience hip fractures than their non-smoking peers. Smoking reduces the oxygenation of bony tissue, reduces the activity of osteogenic cells, and decreases the absorption of calcium from food. Eventually, smoking reduces estrogen in women's body, making them prone to osteoporosis (17). This finding is consistent with that of systematic reviews and primary studies $(18,19)$. Family history had a significant positive association with the occurrence of osteoporosis, such that the risk was almost twice as much. Literature also shows that osteoporosis is transmitted from one generation to another (20-23).

\section{Limitations}

Since this was a cross sectional study, it could not show the temporal precedence of some of the risk factors. Moreover, the validity of our results depended on the quality of data entry in urban and rural health care centers and basic health units. We could not show the association of alcohol on osteoporosis, as we were faced with severe underreporting of this variable (only 3 out of 1779 persons had reported it). If we had entered this variable into the model, we would have had severe bias resulting from a low sample size (24).

\section{Conclusion}

Based on our findings, aging, low education level, living in urban areas, cigarette smoking, and having a family history of osteoporosis were predictive factors for osteoporosis among the elderly.

\section{Acknowledgments}

We would like to thank Katayoon Malaki for proofreading the paper.

\section{Funding}

This work was supported by Hamadan University of Medical Sciences (Grant number: 26996).

Conflict of Interests

The authors declare that they have no competing interests.

\section{References}

1. Cauley JA. Public health impact of osteoporosis. J Gerontol A Biol Sci Med Sci. 2013;68(10):1243-51.

2. Jeremiah MP, Unwin BK, Greenawald MH, Casiano VE. Diagnosis and management of osteoporosis. Am Fam Physician. 2015;92(4):2618.

3. Sforza E, Saint Martin M, Thomas T, Collet P, Garet M, Barthélémy $\mathrm{JC}$, et al. Risk factors of osteoporosis in healthy elderly with unrecognized obstructive sleep apnea: role of physical activity. Sleep Med. 2016;22:25-32.

4. Al-Ani AN, Neander G, Samuelsson B, Blomfeldt R, Ekström W, Hedström M. Risk factors for osteoporosis are common in young and middle-aged patients with femoral neck fractures regardless of trauma mechanism. Acta orthopaedica. 2013;84(1):54-9.

5. Thulkar J, Singh S, Sharma S, Thulkar T. Preventable risk factors for osteoporosis in postmenopausal women: Systematic review and metaanalysis. J Mid-life Health. 2016;7(3):108.

6. Looker AC, Borrud LG, Dawson-Hughes B, Shepherd JA, Wright NC. Osteoporosis or low bone mass at the femur neck or lumbar spine in older adults: United States, 2005-2008. NCHS Data Brief. 2012;93(18.5)

7. Larijani B, Resch H, Bonjour J, Meybodi HA, Tehrani MM. Osteoporosis in Iran, overview and management. Iran J Public Health. 2007:1-13.

8. Irani AD, Poorolajal J, Khalilian A, Esmailnasab N, Cheraghi Z. Prevalence of osteoporosis in Iran: A meta-analysis. J Res Med Sci. 2013;18(9):759-66.

9. Salehi I, Khazaeli S, Najafizadeh SR, Ashraf H, Malekpour M. High prevalence of low bone density in young Iranian healthy individuals. Clin Rheumatol. 2009;28(2):173-7.

10. Abolhassani F, Mohammadi M, Soltani A. Burden of osteoporosis in Iran. Iran J Public Health. 2004:18-28.

11. Kannus P, Sievänen H, Palvanen M, Järvinen T, Parkkari J. Prevention of falls and consequent injuries in elderly people. Lancet. 2005;366(9500):1885-93.

12. Woolf AD, Akesson K. Preventing fractures in elderly people. BMJ. 2003;327(7406):89.

13. Omrani GR, Masoompour SM, Hamidi A, Mardanifard HA, Taghavi SM, Talezadeh $\mathrm{P}$, et al. Bone mineral density in the normal Iranian population: a comparison with American reference data. Arch Osteoporos. 2006;1(1-2):29-35.

14. Moayyeri A, Soltani A, Bahrami H, Sadatsafavi M, Jalili M, Larijani B. Preferred skeletal site for osteoporosis screening in high-risk populations. Public Health. 2006;120(9):863-71.

15. Revelas A, Baltaretsou E, Taxmazidis O. Ageing and osteoporosis. South Afr Fam Pract. 2011;53(3).

16. Ginaldi L, Di Benedetto MC, De Martinis M. Osteoporosis, inflammation and ageing. Immun Ageing. 2005;2(1):14.

17. Jenkins MR D. Smoking status as a predictor of hip fracture risk in postmenopausal women of Northwest Texas. Prev Chronic [Internet]. 2008;5(5). Available from: http://www.cdc.gov/pcd/issues/2008/ jan $/ 07$.

18. Chen H, Liu N, Xu X, Qu X, Lu E. Smoking, radiotherapy, diabetes and osteoporosis as risk factors for dental implant failure: a metaanalysis. PloS One. 2013;8(8):e71955.

19. Ward KD, Klesges RC. A meta-analysis of the effects of cigarette smoking on bone mineral density. Calcif Tissue Int. 2001;68(5):25970 .

20. Kurt-Sirin O, Yilmaz-Aydogan H, Uyar M, Seyhan M-F, Isbir T, Can A. Combined effects of collagen type I alpha1 (COL1A1) Sp1 polymorphism and osteoporosis risk factors on bone mineral density in Turkish postmenopausal women. Gene. 2014;540(2):226-31.

21.Bjarnason NH, Christiansen C. The influence of thinness and smoking on bone loss and response to hormone replacement therapy in early 
postmenopausal women. J Clin Endocrinol Metabol. 2000;85(2):5906.

22. Rapuri P, Gallagher J, Balhorn K, Ryschon K. Smoking and bone metabolism in elderly women. Bone. 2000;27(3):429-36.

23. Kanis JA, Johnell O, Odén A, Johansson H, De Laet C, Eisman JA, et al. Smoking and fracture risk: a meta-analysis. Osteoporos Int. 2005;16(2):155-62.

24. Greenland S, Mansournia MA, Altman DG. Sparse data bias: a problem hiding in plain sight. BMJ. 2016;352:11981. 